\title{
Marketing Authorization Procedure
}

National Cancer Institute

\section{Source}

National Cancer Institute. Marketing Authorization Procedure. NCI Thesaurus. Code C142602.

A formal procedure by which a regulatory agency grants an applicant authorization for the marketing or free distribution of a product after evaluation for safety, efficacy and quality. 